\title{
Insulin-like Growth Factor-1 Is a Potent Neuronal Rescue Agent after Hypoxic-Ischemic Injury in Fetal Lambs
}

\author{
Barbara M. Johnston, E. Carina Mallard, Chris E. Williams, and Peter D. Gluckman \\ Research Center for Developmental Medicine \& Biology, Department of Pediatrics, University of Auckland, Private Bag 92019 , \\ Auckland, New Zealand
}

\begin{abstract}
This study was designed to determine the potential of IGF-1 as a neuronal rescue agent after cerebral ischemia. Unanesthetized late gestation fetal sheep were subjected to 30 -min cerebral ischemia by inflation of carotid artery occluder cuffs. $2 \mathrm{~h}$ later either $0.1 \mu \mathrm{g}$ rhIGF-1, $1 \mu \mathrm{g}$ rhIGF-1, $10 \mu \mathrm{g}$ rhIGF-1, or vehicle was infused into a lateral cerebral ventricle over $1 \mathrm{~h}$. Histologic outcome was assessed $5 \mathrm{~d}$ later. Overall neuronal loss was reduced with $0.1 \mu \mathrm{g}(P<0.05)$ and $1 \mu \mathrm{g}(P<0.002)$ rhIGF-1, but treatment with $10 \mu \mathrm{g}$ was not effective. With $1 \mu \mathrm{g}$ rhIGF-1 neuronal loss scores were significantly lower in brain regions examined including cortex, hippocampus, and striatum, whereas with $0.1 \mu \mathrm{g}$ rhIGF-1 the parietal cortex and thalamus were not improved and the improvement seen in other regions was less than with $1 \mu \mathrm{g}$ rhIGF-1. Treatment with $1 \mu \mathrm{g}$ rhIGF-1 also delayed the onset of seizures and reduced their incidence. Moreover, the secondary phase of cytotoxic edema was reduced and delayed in onset. We conclude that low dose rhIGF-1 therapy promotes neuronal rescue after cerebral hypoxic-ischemic injury in utero, but the effect is dose dependent. Importantly, rhIGF-1 is effective and nontoxic when administered $2 \mathrm{~h}$ after the hypoxic ischemic insult. This distinguishes IGF-1 from most other neuroprotective therapies and suggests clinical application may be possible. (J. Clin. Invest. 1996. 97:300-308.) Key words: cerebral ischemia • encephalopathy $\bullet$ perinatal asphyxia $\cdot$ neuronal rescue $\cdot$ IGF-1
\end{abstract}

\section{Introduction}

Acute hypoxic-ischemic or asphyxial brain injury remains a significant cause of mortality and permanent neurological handicap. It is now recognized that neuronal death can occur in two distinct phases after a transient hypoxic-ischemic injury. Primary neuronal death happens during or immediately after the insult itself and then after a 6-12-h latent interval of electroencephalographic depression, a period of delayed or secondary cell death begins which continues for another $48-72 \mathrm{~h}$.

Address correspondence to Barbara M. Johnston, Research Centre for Developmental Medicine \& Biology, Department of Paediatrics, University of Auckland, Private Bag 92019, Auckland, New Zealand. Phone: 9-3737599 ext. 6434; FAX: 9-3737497; E-mail: b.johnston@ auckland.ac.nz

Received for publication 4 August 1995 and accepted in revised form 3 October 1995.

J. Clin. Invest.

(C) The American Society for Clinical Investigation, Inc.

0021-9738/96/01/300/09 \$2.00

Volume 97, Number 2, January 1996, 300-308
This secondary phase has been characterized both experimentally $(1,2)$ and in human neonates suffering asphyxial injury $(3,4)$. It is believed that the initial insult triggers a complex cascade of cytotoxic reactions which progressively destroy mitochondrial and cellular machinery over many hours, resulting in secondary energy failure and further cell death (5). A variety of mechanisms have been implicated, including apoptosis (6-9). Recognition of the delayed phase of neuronal death has opened up the possibility of applying neuronal rescue therapies some hours after the acute injury with the aim of halting or interfering with the cytotoxic cascade, thereby salvaging brain cells which would otherwise die.

The observations of Nieto-Sampedro et al. (10), in which a marked induction of neurotrophic activity was noted in the cerebral cortex several days after traumatic brain injury, provided the stimulus for subsequent research into the role of endogenous growth factors in the response of the brain to injury. Insulin-like growth factor-1 (IGF-1) is a peptide growth factor which acts via both endocrine and autocrine/paracrine mechanisms and has both pleiotropic and metabolic actions. Both IGF-1 (11-13) and it's receptor, the type-1 receptor (IGF-1R) (14-16) are present in most brain regions. In the rat brain IGF-1 mRNA and protein levels peak in infancy (17-19). IGF-1 is now also recognized as important for wound healing and tissue repair (20) and in most tissues, including brain, the paracrine IGF system is activated in response to injury. Increased expression of mRNA coding for IGF-1, together with that for the IGF binding proteins IGFBP-2 and IGFBP-3 occurs in response to unilateral hypoxic ischemic injury in the infant rat $(21,22)$ or in response to focal ischemia in adult rats (23). Also, extracellular IGF-1 levels are reported to rise after electrolytic lesions of the hippocampus (24). Moreover, treatment with exogenous IGF-1 is reported to enhance the survival of neurons in vitro (25-27) and facilitate peripheral nerve regeneration (28). In vivo, central administration of IGF-1 to adult rats after exposure to transient hypoxia-ischemia reduces both neuronal loss (21) and the incidence of cortical infarction (29) in a dose dependent manner. Thus, IGF-1 has been proposed to play an important role in the rescue of injured neurons in the adult brain, although the mechanisms by which it does so remain unclear (29).

The present study was designed to examine the doseresponse effects of IGF-1 treatment in a model of hypoxic ischemic encephalopathy in the unanesthetized late gestation fetal sheep. This preparation is particularly useful for studying the evolution of brain injury as it allows a severe global ischemic injury to be induced and physiologically monitored over several days without the confounding effects of intensive support and anesthesia. Because of the clinical importance of perinatal asphyxia and the potential for early application of neuronal rescue therapies in the neonate, this preparation has added relevance. We report a significant reduction in histologically assessed neuronal loss after central infusion of recombi- 
nant human (rh) ${ }^{1}$ IGF-1, together with an attenuated and delayed-onset phase of secondary neuronal death. These therapeutic effects were achieved even though IGF-1 was not administered until $2 \mathrm{~h}$ after the hypoxic-ischemic insult. The efficacy of postinsult treatment distinguishes IGF-1 from most other neuroprotective therapies and suggests the possibility of clinical application.

\section{Methods}

Surgical procedures. The studies were performed on time-mated late gestation fetal sheep. All animal procedures were carried out with the approval of the Animal Ethics Committee of the University of Auckland. Using sterile surgical techniques, pregnant sheep were operated on under $2 \%$ halothane $/ \mathrm{O}_{2}$ general anesthesia at $119-126 \mathrm{~d}$ gestation as previously described (1). Briefly, the fetal head, neck, and forelimbs were exteriorized via a maternal hysterotomy. Polyvinyl catheters were implanted into both axillary arteries, one jugular vein, and the amniotic sac. The vertebro-occipital anastomoses were ligated bilaterally in order to restrict the cerebral blood supply to the carotid arteries. A double-ballooned inflatable silicone cuff was placed on each carotid artery. Three pairs of shielded multistranded stainless steel fine wire (AS633; Cooner Wire Co., Chatsworth, CA) electrodes were placed via burr holes in the skull, onto the dura overlying the parietal cortex. For recording electrocortical activity $(\mathrm{ECoG})$ the electrodes were placed $10 \mathrm{~mm}$ bilaterally from the midline at 5 and 15 $\mathrm{mm}$ anterior to bregma. To measure cortical impedance $(\mathrm{CI})$ the third pair of electrodes was placed $10 \mathrm{~mm}$ anterior to bregma and 15 $\mathrm{mm}$ bilateral to the midline. A reference electrode was sewn under the fetal scalp. A cannula constructed from an angled 18-gauge needle attached to a saline-filled catheter (dead space $0.7 \mathrm{ml}$ ) was implanted into the right lateral cerebral ventricle as described previously (30). The fetus was returned to the uterus and lost amniotic fluid was replaced with warm $\left(39^{\circ} \mathrm{C}\right)$ saline to which $80 \mathrm{mg}$ gentamicin was added. The uterus was closed in two layers and all catheters and electrodes exteriorized to the ewe's flank. The abdominal wall of the ewe was closed and a polyvinyl catheter inserted into the maternal tarsal vein.

Postoperative procedures and data collection. After the operation the ewes were housed in individual cages at constant temperature $\left(17^{\circ} \mathrm{C}\right)$ and humidity $(50 \%)$ and in a 12-h light/dark cycle. The ewes were given free access to water and hay, supplemented by sheep nuts and alfalfa. Antibiotics ( $80 \mathrm{mg}$ gentamicin, i.am. and $2 \mathrm{ml}$ streptopen i.m. to the ewe) were administered daily. The lateral ventricle catheter was flushed each day with $0.3 \mathrm{ml}$ sterile artificial cerebrospinal fluid (CSF) (31) in order to maintain catheter patency. Fetal arterial blood samples were taken each day for blood gas and $\mathrm{pH}$ analysis (Radiometer ABL 330) as well as measurement of blood glucose and lactate (YSI 2300; Yellow Springs Instruments). Both ewe and fetus were allowed $4 \mathrm{~d}$ to recover from surgery before the experiment was begun.

From 12-24 h after surgery until the fetus was sacrificed, continuous recordings of fetal ECoG and cortical impedance (CI) were displayed on a polygraph together with fetal arterial pressure corrected for changes in amniotic pressure by an electronic subtraction circuit. The ECoG signal was amplified 5000 times and low-pass filtered using an eighth-order switched capacitor Butterworth filter with the cut-off frequency set with the $-3 \mathrm{~dB}$ point at $30 \mathrm{~Hz}$. A four-electrode technique was used to measure cortical impedance as described previously (2). Briefly, current was injected through the pair of cortical stimulating electrodes and the impedance signal extracted from the ECoG signal. An IBM-compatible PC-AT286 was used to collect

1. Abbreviations used in this paper: $\mathrm{CI}$, cortical impedance; CSF, cerebrospinal fluid; ECoG, electrocorticogram; IGFBP, insulin-like growth factor binding protein; rh, recombinant human.
ECoG and impedance signals for $12 \mathrm{~h}$ before occlusion and for $120 \mathrm{~h}$ afterwards. ECoG power spectra were obtained using real-time spectral analysis (32) and the ECoG spectra and impedance measurements were averaged over 5.5 min intervals and each block of data stored to disk.

Experimental procedures. Studies commenced $4 \mathrm{~d}$ after surgery on fetuses aged 123-130 d gestation. Fetal arterial blood samples were collected onto ice at 15 and $1 \mathrm{~min}$ before occlusion. Studies were only carried out on fetuses with a $\mathrm{PO}_{2}>18 \mathrm{mmHg}$ and $\mathrm{pH}>7.32$ and whose blood glucose and lactate measurements fell within the normal range for this laboratory of $0.7-1.2 \mathrm{mM}$. Reversible cerebral ischemia was achieved by carotid artery occlusion after bilateral inflation of the carotid cuffs with sterile saline. Successful occlusion was confirmed with the rapid onset of an isoelectric ECoG. After $30 \mathrm{~min}$ a fetal arterial sample was collected and the cuffs deflated. Additional fetal arterial samples for blood gas, $\mathrm{pH}$, glucose and lactate analysis were collected at $1,2,3,4,8,12,24,48,72,96$, and $120 \mathrm{~h}$ after the start of occlusion.

The fetuses were randomly assigned to one of four groups; three groups of six fetuses to be treated with different doses of IGF-1 and the control group to receive an equivalent volume of vehicle only. Recombinant human (rh) IGF-1 (generously donated by Kabi Pharmacia, Stockholm, Sweden) was supplied as a $2 \mathrm{mg} / \mathrm{ml}$ solution in phosphate buffered saline with a $\mathrm{pH}$ of 6.0. It was diluted with artificial CSF to concentrations of $0.1,1$, or $10 \mu \mathrm{g} / \mathrm{ml}$ rhIGF- 1 and the $\mathrm{pH}$ adjusted to $7.33-7.39$ with $1 \mathrm{M} \mathrm{NaHCO}_{3}$ containing $1 \%$ bovine serum albumin. The vehicle infusion for the control group was $50 \mu$ phosphate-buffered saline (Kabi Pharmacia, Stockholm, Sweden) added to $1 \mathrm{ml}$ artificial $\mathrm{CSF}$ and the $\mathrm{pH}$ adjusted to 7.33-7.39 as above. rhIGF-1 and vehicle solutions were both sterilized by injection through a $0.22-\mu \mathrm{m}$ millipore filter. The dead space in the lateral ventricle catheter $(0.7 \mathrm{ml})$ was primed with rhIGF- 1 or vehicle by infusing $0.7 \mathrm{ml}$ over $15-20 \mathrm{~min}$. Beginning $2 \mathrm{~h}$ after the start of carotid artery occlusion either $0.1,1.0$, or $10 \mu \mathrm{g}$ rhIGF-1 was infused into the lateral ventricle in a volume of $1 \mathrm{ml}$ over $1 \mathrm{~h}$ using a syringe pump (Harvard Apparatus, S. Natick, MA). Control fetuses received $1 \mathrm{ml}$ of vehicle infused likewise over $1 \mathrm{~h}$. Data collection continued for $120 \mathrm{~h}$ after the ischemic insult before the ewe and fetus were killed by barbiturate overdose.

Histological analysis. The fetal brain was perfused immediately through the carotid arteries with $500 \mathrm{ml}$ saline, followed by $500 \mathrm{ml}$ $10 \%$ phosphate-buffered formalin. The fixed brain was stored in $10 \%$ formalin for at least $7 \mathrm{~d}$ before embedding in paraffin wax. Coronal sections were cut $8 \mu \mathrm{m}$ thick and every 40th section stained with thionine and acid fuchsin as described previously (33). Each section was examined by light microscopy at $100 \times$ and $400 \times$ by an assessor blind to the treatment groupings. Neurons showing ischemic cell change, identified as acidophilic (red) cytoplasm with contracted or pyknotic nuclei were classified as dead (34). Neuronal loss was scored in preselected areas of the parasagittal cortex, lateral cortex, striatum, dorsal, and ventral hippocampus, including dentate gyrus and CA1-4, the thalamus and amygdala. The proportion of dead neurons in each region was scored as described previously (33) according to the scale: no dead neurons $=0 ;>0-10 \%=5 ; 11-50 \%=30 ; 51-90 \%=70 ; 91-$ $99 \%=95$; and $100 \%$ dead neurons $=100$. Each score represents the mid-point of its range and average scores were calculated for each region.

Data analysis and statistics. Off-line analysis of the averaged ECoG power spectra and CI signal was done using a scientific software package (Asystant; Macmillan Software Co., New York). The total ECoG intensity was derived from $1-30 \mathrm{~Hz}, \log$-transformed and expressed in decibels (dB). Both ECoG intensity and CI were normalized with respect to the $12 \mathrm{~h}$ baseline period before carotid occlusion, with CI expressed as a percentage of baseline. Short term fluctuations in ECoG intensity were minimized by smoothing with a digital Blackman low-pass filter set with a cut-off of 0.1 cycles/point. ECoG intensity, ECoG spectral edge (lower $90 \%$ of frequency) and CI were measured at $12,24,36,48,72,96$, and $120 \mathrm{~h}$ after initiation of the is- 
Table I. Baseline Fetal Blood Gas and Metabolic Status and Body and Brain Weight at Postmortem

\begin{tabular}{lcccc}
\hline & Vehicle & $0.1 \mu \mathrm{g}$ rhIGF-1 & $1.0 \mu \mathrm{g}$ rhIGF-1 & $10 \mu \mathrm{g}$ rhIGF-1 \\
\hline $\mathrm{PO}_{2}(\mathrm{mmHg})$ & $24.4 \pm 1.4$ & $22.1 \pm 0.8$ & $23.2 \pm 0.8$ & $22.2 \pm 2.1$ \\
$\mathrm{PCO}_{2}(\mathrm{mmHg})$ & $52.9 \pm 0.6$ & $50.4 \pm 1.3$ & $52.6 \pm 1.4$ & $52.3 \pm 1.1$ \\
$\mathrm{pH}$ & $7.378 \pm .004$ & $7.379 \pm .011$ & $7.378 \pm .004$ & $7.374 \pm .008$ \\
Glucose $(\mathrm{mM})$ & $0.9 \pm 0.03$ & $1.0 \pm 0.09$ & $0.9 \pm 0.06$ & $1.0 \pm 0.08$ \\
Lactate $(\mathrm{mM})$ & $1.1 \pm 0.1$ & $0.9 \pm 0.09$ & $0.9 \pm 0.09$ & $3.6 \pm 0.76$ \\
Fetal weight (kg) & $3.17 \pm 0.14$ & $3.24 \pm 0.15$ & $48.1 \pm 6.3$ & $3.49 \pm 0.35$ \\
Brain weight (grams) & $46.5 \pm 5.1$ & $42.7 \pm 1.3$ & & $45.5 \pm 1.9$ \\
& & & & \\
\hline
\end{tabular}

chemic insult. In addition minimum and peak ECoG power intensity were measured from the smoothed time series, as was the time to peak ECoG intensity. For CI, the height of the acute and secondary peaks was measured and the time to onset of the secondary rise and time to secondary peak in CI determined.

Seizures were identified from the polygraphic raw ECoG recording as periods of paroxysmal high voltage $(>1 \mathrm{mV})$ low frequency discharges of $>30 \mathrm{~s}$ duration. The number of seizures per hour was counted at 6-h intervals from the polygraph trace and the time to onset of seizures noted. The polygraphic recordings were also examined visually for evidence of a return to the preocclusion pattern of ECoG cycling between high and low voltage sleep states that is normally observed in late gestation fetal sheep.

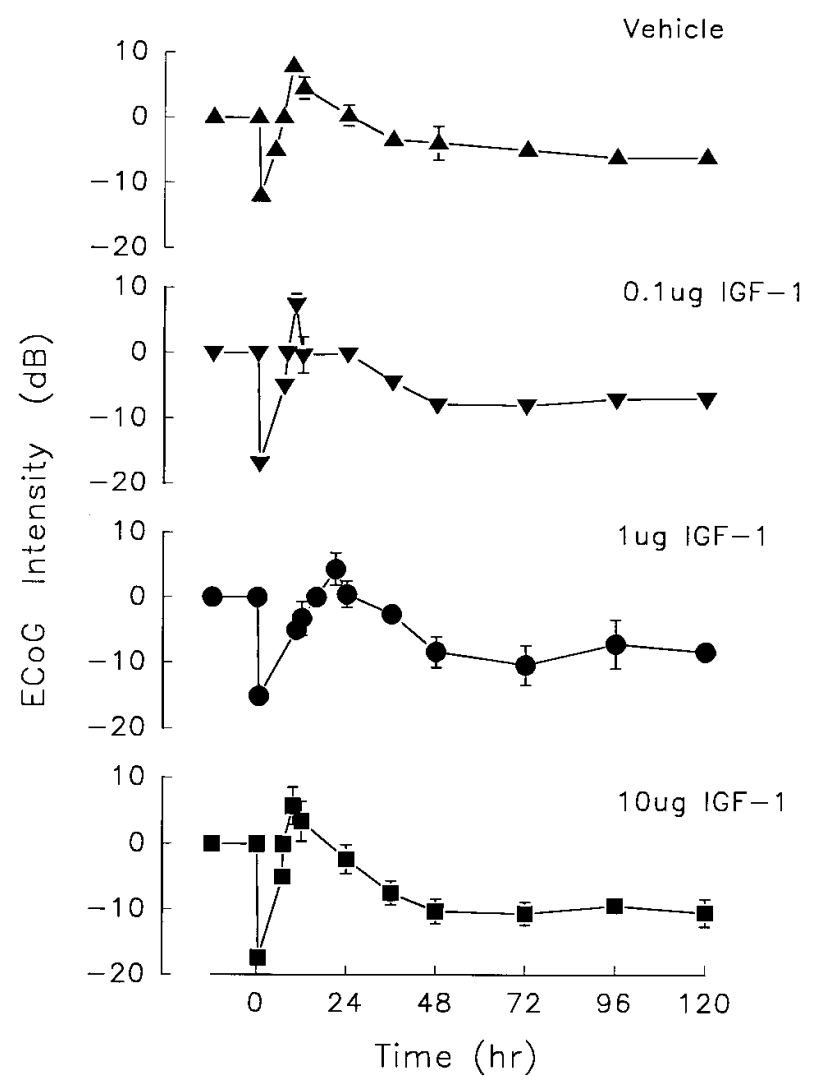

Figure 1. Effect of rhIGF-1 administration on time course of changes in ECoG intensity after 30 min of cerebral hypoxia-ischemia. A 1-h

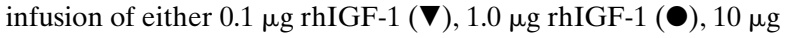
rhIGF-1 ( $)$, or vehicle $(\boldsymbol{\Delta})$ was started $2 \mathrm{~h}$ after initiation of cerebral ischemia. In vehicle treated fetuses ECoG intensity was depressed for up to $8 \mathrm{~h}$ before a transition to high intensity seizure activity. In fetuses treated with $1 \mu \mathrm{g}$ rhIGF-1 the time to peak ECoG intensity was delayed and there was a trend towards a reduction in peak amplitude.
The effect of each dose of rhIGF-1 treatment on histological neuronal loss and each biophysical parameter was compared with vehicle using two-way analysis of variance with time or brain region as repeated measures as appropriate. When overall differences were significant, post hoc comparisons were made using the Neuman-Keuls multiple comparison test or paired Student $t$ test. Differences in the proportion of fetuses in which the ECoG returned to normal cycling were analyzed using the Chi-Square test. All data are presented as means \pm SE.

\section{Results}

A total of 32 fetal sheep were subjected to bilateral carotid artery occlusion. In five the ECoG did not become isoelectric, due either to an occluder cuff bursting on inflation (three ani-

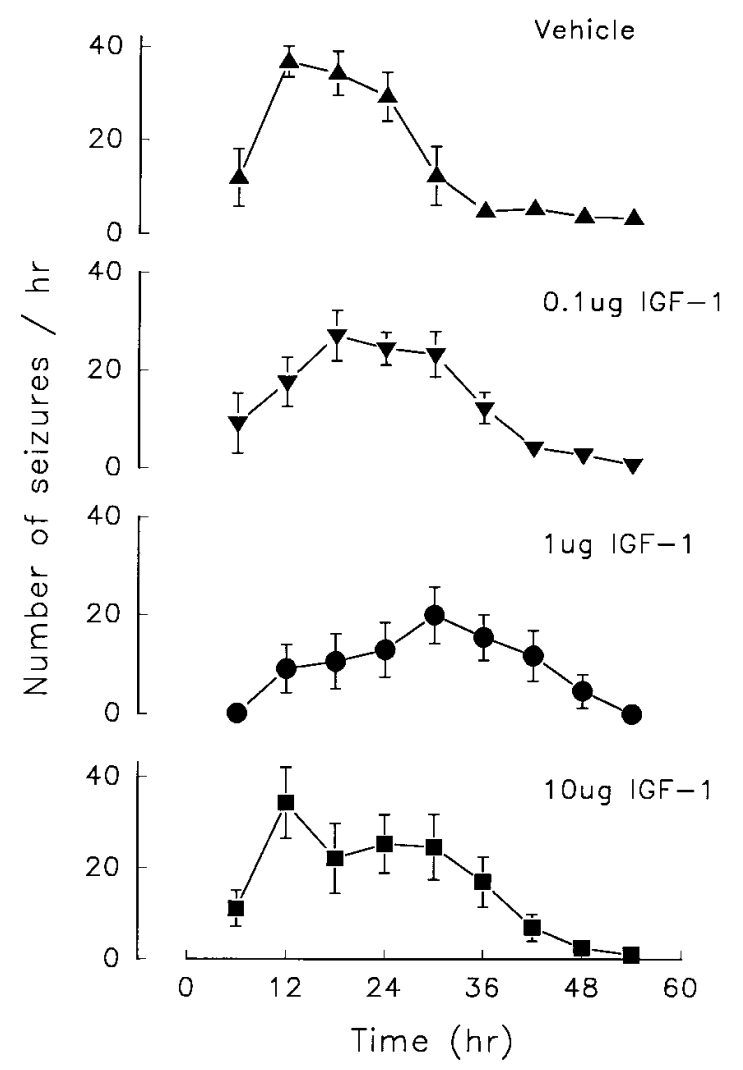

Figure 2. Effect of rhIGF-1 administration on frequency of cortical seizures after $30 \mathrm{~min}$ of cerebral hypoxia-ischemia. The number of seizures occurring over periods of $1 \mathrm{~h}$ was counted at 6-h intervals from visual inspection of polygraph recordings of electrocortical activity. Maximum seizure rate was reduced after treatment with $1 \mu \mathrm{g}$ rhIGF-1. 
Table II. Dose-Response Effects of rhIGF-1 on Time Course of Changes in Fetal ECoG Intensity

\begin{tabular}{|c|c|c|c|c|}
\hline & Vehicle & $0.1 \mu \mathrm{g}$ rhIGF-1 & $1.0 \mu \mathrm{g}$ rhIGF-1 & $10 \mu \mathrm{g}$ rhIGF-1 \\
\hline Time to onset of seizures (h) & $5.4 \pm 0.4$ & $6.0 \pm 0.8$ & $11.5 \pm 2.0 *$ & $5.9 \pm 0.9$ \\
\hline Time to peak ECoG intensity (h) & $9.2 \pm 0.7$ & $10.1 \pm 1.4$ & $21.0 \pm 3.9 *$ & $9.7 \pm 1.2$ \\
\hline Peak ECoG intensity (dB) & $7.8 \pm 1.5$ & $7.4 \pm 1.6$ & $4.4 \pm 2.5$ & $5.7 \pm 2.8$ \\
\hline Final ECoG intensity (dB) & $-6.1 \pm 1.4$ & $-6.9 \pm 1.0$ & $-8.4 \pm 1.3$ & $-10.5 \pm 2.1$ \\
\hline Number returning to ECoG cycling & $1 / 6$ & $5 / 6^{*}$ & $5 / 6^{*}$ & $3 / 6$ \\
\hline Time to return of ECoG cycling (h) & 53 & $69.8 \pm 7.7$ & $61.5 \pm 10.3$ & $65.7 \pm 10.3$ \\
\hline
\end{tabular}

$* P<0.05$ compared with vehicle.

Table III. Effect of rhIGF-1 Treatment on Spectral Edge Frequency

\begin{tabular}{lrrrr}
\hline & Vehicle & $0.1 \mu \mathrm{g}$ rhIGF-1 & $1.0 \mu \mathrm{g}$ rhIGF-1 & $10 \mu \mathrm{g}$ rhIGF-1 \\
\hline Pre-occlusion spectral edge frequency (Hz) & $12.6 \pm 0.7$ & $12.8 \pm 0.5$ & $13.8 \pm 0.6$ & $12.1 \pm 0.6$ \\
Average post-treatment (3-120 h) spectral edge frequency (Hz) & $6.2 \pm 0.4$ & $8.7 \pm 0.6^{*}$ & $8.5 \pm 0.6^{*}$ & $7.1 \pm 0.5$ \\
& & & \\
\hline
\end{tabular}

${ }^{*} P<0.015$ compared with vehicle.

mals) or presumed incomplete ligation of the vertebro-occipital anastomoses so that cerebral ischemia was not complete (two animals). In a further three fetuses the ECoG was isoelectric during carotid artery occlusion, but regained much of it's former amplitude during the following $2 \mathrm{~h}$ before treatment was due to be administered. All eight such fetuses were excluded from further study. The remaining 24 animals were assigned in equal numbers to each of the four treatment groups. There were no differences in mean gestational age, preocclusion blood gas, $\mathrm{pH}$, glucose or lactate levels between the groups, and neither fetal weight nor brain weight were different when recorded at post-mortem $5 \mathrm{~d}$ later (Table I). Preocclusion fetal blood pressure did not differ between groups and there was no effect of rhIGF-1 treatment on fetal blood pressure during the $5 \mathrm{~d}$ after cerebral ischemia.

ECoG activity was rapidly ( $<30 \mathrm{~s}$ ) suppressed during carotid artery occlusion and remained depressed for several hours in all fetuses, before a transition to high amplitude low frequency epileptiform activity, which corresponded with clearly identifiable seizures on the polygraph recording of ECoG. Fig. 1 shows the time course of changes in ECoG intensity for each group of fetuses. For those treated with $1 \mu \mathrm{g}$ rhIGF-1, both the onset of seizures and the time to peak ECoG intensity were significantly $(P<0.02)$ delayed compared with vehicle controls (Table II). In addition maximum seizure rate was reduced $(P<0.03)$ after treatment with $1 \mu \mathrm{g}$ rhIGF-1 (Fig. 2), but the trend towards a lower peak ECoG intensity was not significant. Although rhIGF-1 treatment had no effect on final ECoG intensity (Table II), the proportion of fetuses in which the ECoG returned to the normal pattern of cycling between high and low voltage sleep states was increased $(P<0.04$, Chi-Square test) in the $0.1 \mu \mathrm{g}$ and $1 \mu \mathrm{g}$ rhIGF-1 treated groups (Table II). In addition, there was a significant treatment group effect on overall ECoG spectral edge frequency between 3 and $120 \mathrm{~h}$ after occlusion with both the $0.1 \mu \mathrm{g}$ rhIGF-1- and $1 \mu \mathrm{g}$ rhIGF-1-treated groups showing increased $(P<0.015)$ frequency (Table III).

The time course of the changes in $\mathrm{CI}$ is shown in Fig. 3. CI rose progressively during occlusion, peaking at similar levels in all four groups (Table IV) within 2-4 min of occlusion release, before declining towards preinsult levels. At $2 \mathrm{~h}$ after occlusion, when rhIGF-1 or vehicle infusion was commenced, the extent of residual intracellular edema did not differ be-

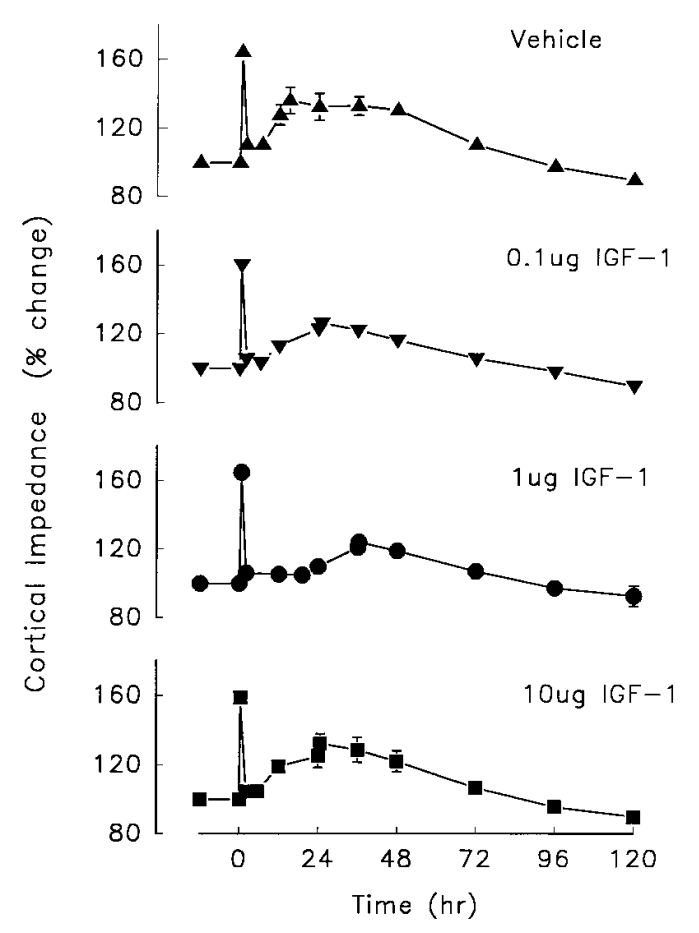

Figure 3. Effect of rhIGF-1 administration on time course of changes in cortical impedance (CI) after $30 \mathrm{~min}$ of cerebral hypoxia-ischemia. A rapid primary rise in $\mathrm{CI}$ was seen during carotid occlusion in all fetuses. This had largely resolved by $2 \mathrm{~h}$ after ischemia when infusion of rhIGF-1 or vehicle was started. In all groups there was a secondary rise in CI several hours after the initial injury, but this was significantly $(P<0.001)$ postponed in those treated with $1 \mu \mathrm{g}$ rhIGF-1. 
Table IV. Dose-Response Effects of rhIGF-1 on Time Course of Cortical Impedance Changes

\begin{tabular}{|c|c|c|c|c|}
\hline & Vehicle & $0.1 \mu \mathrm{g}$ rhIGF-1 & $1.0 \mu \mathrm{g}$ rhIGF-1 & $10 \mu \mathrm{g}$ rhIGF-1 \\
\hline Primary peak impedance (percentage change) & $164 \pm 5.0$ & $160 \pm 3.3$ & $164 \pm 4.7$ & $159 \pm 4.5$ \\
\hline Secondary peak impedance (percentage change) & $136 \pm 7.6$ & $126 \pm 2.8$ & $124 \pm 3.8$ & $132 \pm 5.7$ \\
\hline Time to onset of impedance rise $(\mathrm{h})$ & $6.8 \pm 0.6$ & $6.4 \pm 0.9$ & $19.2 \pm 2.2^{\ddagger}$ & $5.5 \pm 0.6$ \\
\hline Time to secondary impedance peak (h) & $14.9 \pm 1.9$ & $25.0 \pm 3.2 *$ & $36.4 \pm 1.7^{\ddagger}$ & $24.7 \pm 4.6$ \\
\hline
\end{tabular}

$* P<0.05$

$¥ P<0.001$ compared with vehicle.

tween treatment groups; CI ranged from $104.7 \pm 2.3 \%$ to $110.4 \pm 2.3 \%$. A secondary rise in $\mathrm{CI}$, reflecting cytotoxic edema that is associated with a delayed phase of neuronal death (2), was observed in all groups (Fig. 3). The timing of the onset of the secondary increase in CI coincided with the start of seizure activity and did not differ between vehicle and 0.1 or $10 \mu \mathrm{g}$ rhIGF-1 treated groups. However, in fetuses treated with $1 \mu \mathrm{g}$ IGF-1 the secondary rise in CI was significantly $(P<$ 0.001 ) delayed (Table IV) and dissociated from the onset of seizures $(P<0.05)$. The time to peak secondary CI was delayed for both the $0.1 \mu \mathrm{g}(P<0.03)$ and $1 \mu \mathrm{g}(P<0.001)$ rhIGF-1 treated groups, and there was a trend towards attenuation of the secondary CI peak (Table IV).

Primary and secondary peaks in circulating blood glucose (Fig. 4) and blood lactate (Fig. 5) levels were also observed after cerebral ischemia. In control animals blood glucose rose from $0.9 \pm 0.03$ to $1.45 \pm 0.16 \mathrm{mM}$ after 30 min occlusion and
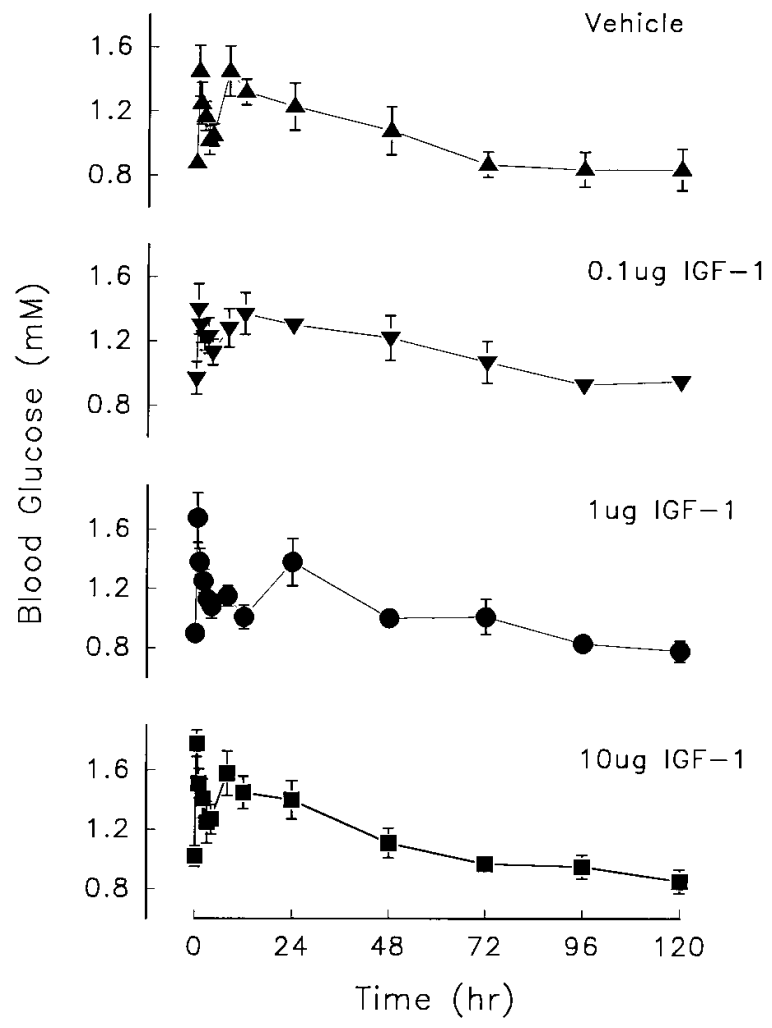

Figure 4. Biphasic increase in systemic blood glucose concentration after $30 \mathrm{~min}$ of cerebral hypoxia-ischemia. The secondary peak was delayed $(P<0.007)$ in fetuses treated with $1 \mu \mathrm{g}$ rhIGF-1. then declined before rising again to a peak of $1.45 \pm 0.16 \mathrm{mM}$ at $8 \mathrm{~h}$ after occlusion. A similar pattern was seen in the fetuses treated with either 0.1 or $10 \mu \mathrm{g}$ rhIGF-1 (Fig. 4), but treatment with $1 \mu \mathrm{g}$ rhIGF-1 delayed $(P<0.007)$ the secondary peak to $24 \mathrm{~h}$ after occlusion (Fig. 4). Biphasic changes were also noted in blood lactate levels but the primary and secondary peaks were greater and occurred later than the rise in blood glucose. Blood lactate rose in control fetuses from 1.1 $\pm 0.1 \mathrm{mM}$ to peak at $3.9 \pm 0.8 \mathrm{mM} 1 \mathrm{~h}$ after start of occlusion before declining and then rising to $8.2 \pm 1.7 \mathrm{mM} 12 \mathrm{~h}$ after occlusion (Fig. 5). Treatment with $1 \mu \mathrm{g}$ rhIGF-1 significantly delayed $(P<0.004)$ and attenuated $(P<0.008)$ the secondary blood lactate peak, while 0.1 and $10 \mu \mathrm{g}$ IGF-1 did not significantly affect the timing or the concentration at which blood lactate levels peaked.

Histologic examination of the vehicle-infused brains $5 \mathrm{~d}$ af-

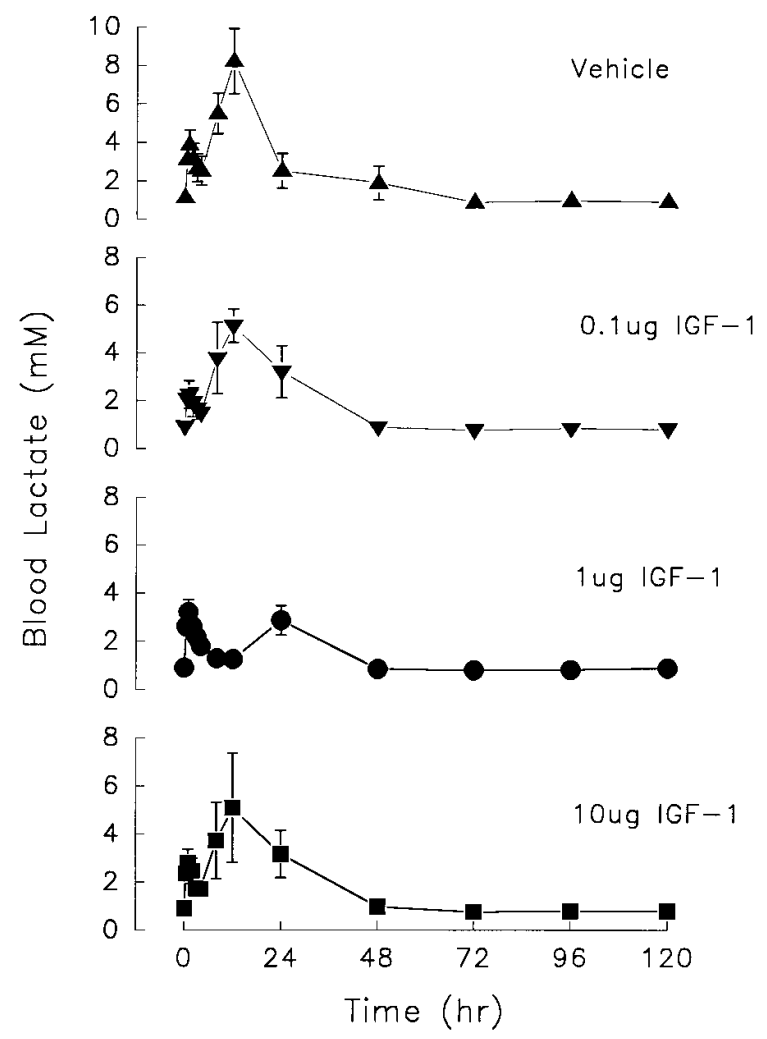

Figure 5. Time course of changes in systemic blood lactate levels after $30 \mathrm{~min}$ of cerebral hypoxia-ischemia. In vehicle-treated fetuses there was a large secondary peak in blood lactate levels at $12 \mathrm{~h}$ after insult. This was attenuated in the group treated with $0.1 \mu \mathrm{g}$ rhIGF-1 and delayed and almost abolished in those treated with $1 \mu \mathrm{g}$ rhIGF-1. 


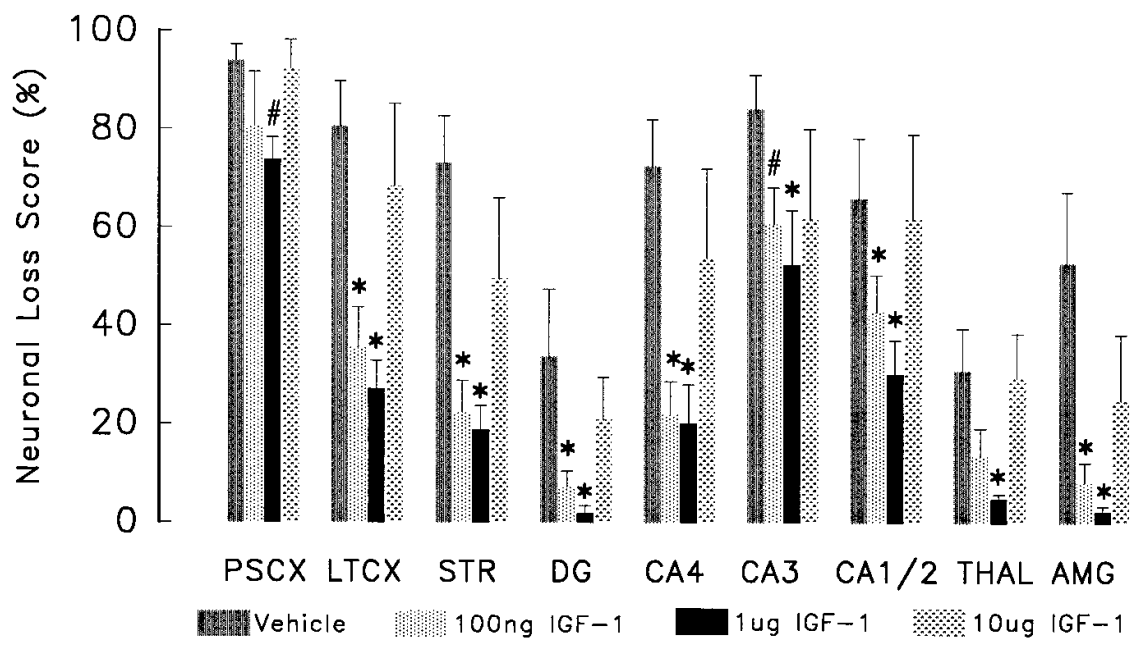

Figure 6. Effect of rhIGF-1 treatment on histologically assessed neuronal loss in nine brain regions at $5 \mathrm{~d}$ after $30 \mathrm{~min}$ of cerebral hypoxiaischemia. A significant reduction in neuronal loss was seen in all regions in those given $1 \mu \mathrm{g}$ rhIGF-1 and a lesser, but significant, reduction in neuronal loss in fetuses treated with $0.1 \mu \mathrm{g}$ rhIGF-1. PSCX, parasagittal cortex; $L T C X$, lateral cortex; STR, striatum; $C A 1 / 2,3,4$, cornu ammonis of hippocampus; $D G$, dentate gyrus; $T H A L$, thalamus; $A M G$, amygdala. $\# P<0.05 ; * P<0.01$.

ter occlusion revealed widespread damage in a "watershed" pattern, with the parasagittal cortex suffering laminar necrosis. Extensive neuronal loss, similar to that previously observed (33), was apparent throughout the lateral cortex, striatum and hippocampus (Fig. 6), while amygdala, thalamus and dentate gyrus exhibited moderate to severe neuronal loss. In contrast, overall neuronal loss was significantly reduced after treatment with $0.1 \mu \mathrm{g}$ rhIGF-1 $(P<0.05)$ or $1 \mu \mathrm{g}$ rhIGF-1 $(P<0.002)$. With $1 \mu \mathrm{g}$ rhIGF-1, significant improvement in neuronal loss score was seen in each of the nine brain regions examined. The greatest protection was observed in subcortical structures, particularly the thalamus, amygdala, dentate gyrus and striatum. Treatment with $0.1 \mu \mathrm{g}$ rhIGF-1 did not reduce neuronal loss significantly in the parasagittal cortex or thalamus and the improvement seen in the other regions was less than with $1 \mu \mathrm{g}$ rhIGF-1 (Fig. 6). Treatment with $10 \mu \mathrm{g}$ rhIGF-1 was not effective.

\section{Discussion}

In this study, we used a model of hypoxic-ischemic encephalopathy in the unanesthetized late gestation fetal sheep, and demonstrated significant improvement in outcome following treatment with a single dose of rhIGF-1 given $2 \mathrm{~h}$ after the hypoxic-ischemic insult. Central administration of $1 \mu \mathrm{g}$ rhIGF-1 reduced neuronal loss in each brain region examined, with greatest effect seen in the thalamus, amygdala and dentate gyrus where $<5 \%$ of neurons died. With $0.1 \mu \mathrm{g}$ rhIGF- 1 there was significant improvement in all regions except the parasagittal cortex and thalamus, but the reduction in neuronal loss was less than with $1 \mu \mathrm{g}$ rhIGF-1.

Our experimental model, in which reversible cerebral hypoxia-ischemia is induced by occluding both carotid arteries for $30 \mathrm{~min}$, has been described previously $(1,2,33)$, and shows many characteristics of hypoxic-ischemic encephalopathy in asphyxiated infants. Use of the fetus in utero offers several advantages. Reversible cerebral hypoxic-ischemic injury can be induced without the confounding effects of anesthesia. Moreover, stability of fetal brain and environmental (amniotic) temperature is maintained maternally, which obviates problems of thermal influences affecting outcome $(35,36)$. In addition fetal oxygen and nutrient supply are controlled via the placenta, and so respiratory and hemodynamic fluctuations are avoided.
Thus the pathophysiological responses to a single episode of cerebral ischemia can be studied in an otherwise stable fetus.

The delayed appearance of electroencephalographic seizures and cortical cytotoxic edema associated with the development of cortical laminar necrosis and secondary neuronal death is believed to correspond to the secondary energy failure recorded by phosphorus magnetic resonance spectroscopy in newborn infants who suffer perinatal asphyxia $(3,4)$. Likewise, the secondary rise in blood glucose and lactate levels noted in the vehicle treated fetuses in this study probably reflects increased cerebral lactate production, consequent on mitochondrial energy failure causing high energy phosphate production to decline, which in turn leads to anaerobic glycolysis, increased lactate production and decreased glucose uptake (37). In addition, a contributory factor to high blood lactate levels may be the continuous seizure activity observed in vehicle treated fetuses. It is notable that rhIGF-1 administration both attenuated and delayed the appearance of all pathophysiological markers associated with secondary cell death. The $1 \mu \mathrm{g}$ dose of rhIGF-1 delayed the onset, and reduced the rate of cortical seizures. Also, the secondary rise in cortical impedance that reflects the development of cytotoxic intracellular edema (2) was postponed and dissociated temporally from the onset of seizures. Moreover, the secondary peak in blood lactate was delayed and largely abolished after treatment with 1 $\mu \mathrm{g}$ rhIGF-1. This suggests an action of rhIGF-1 to delay the onset of secondary energy failure and reduce its severity, and/ or a possible indirect effect via reduced seizure frequency.

Our finding that rhIGF-1 treatment was least effective in the parasagittal cortex is surprising because it contrasts with previous studies in the adult rat $(21,29)$ where the greatest reduction in neuronal loss was seen in the frontoparietal cortex when rhIGF-1 was given $2 \mathrm{~h}$ after unilateral hypoxia-ischemia. It may be that 30 -min cerebral ischemia in the fetal sheep causes a greater degree of primary neuronal loss in the cerebral cortex than does 10-min unilateral hypoxia-ischemia in the adult rat. Indeed, the residual rise in cortical impedance seen at $2 \mathrm{~h}$ is thought to indicate irreversible damage before rhIGF-1 therapy was commenced (38). Alternatively, there may be developmental or species differences in the distribution of IGF-1 receptors between the fetal sheep and adult rat brain. Although there is evidence in the rat that cerebral IGF-1 receptors are more abundant in fetal life than in adulthood 
(39) another study suggests a constant constitutive pattern of brain IGF-1 receptor expression between embryonic and adult life, upon which local patterns of increased intensity are superimposed at certain times in development (40). However, we are not aware of any data on the ontogeny or distribution of type-1 IGF receptors in the sheep brain.

Even though the parasagittal cortex showed least improvement as measured by the reduction in neuronal loss, there was evidence of enhanced cortical function. rhIGF-1 treatment was associated with augmentation of the ECoG spectral edge frequency towards preinjury levels. In addition, in five of six fetuses treated with 0.1 or $1 \mu \mathrm{g}$ rhIGF-1 the cessation of seizures was accompanied by the reappearance of the normal late gestation differentiated pattern of electrocortical activity. This normally occurs between 115-120 d gestation as the ECoG becomes organized into the clear episodes of high and low voltage activity, considered equivalent to postnatal quiet and rapid-eye movement sleep states. It is possible that such effects could be attributed more to increased survival of cortically projecting neurons from thalamic nuclei involved in electrocortical synchronization or desynchronization, than to the observed limited reduction in parasagittal neuronal loss. Indeed, the lack of improvement in final ECoG intensity in the rhIGF-1 treated fetuses probably reflects the relatively weak effect of rhIGF-1 in rescuing parasagittal neurons because loss of ECoG intensity at $72 \mathrm{~h}$ after ischemia is known to correlate with the degree of laminar necrosis in the underlying cortex (33).

Treatment with $1 \mu \mathrm{g}$ rhIGF-1 was also associated with a beneficial effect on seizure rate. This too, may represent an indirect effect, possibly arising from the marked reduction in striatal neuronal loss effected by rhIGF-1 treatment. We recently reported that loss of inhibitory GABA-ergic striatal neurons as a result of repeated ischemic or asphyxial insults can cause intermittent cortical seizures even when damage to the cortex itself is minimal (41). Thus, it follows that as loss of striatal neurons can contribute to the development of cortical seizures, then increased preservation of striatal neurons will likely reduce the incidence of such seizures. Similarly, it is possible that the reduced incidence of cortical seizures observed after rhIGF-1 treatment may, in itself, contribute to the reduced neuronal loss in the lateral cortex and hippocampus, since prolonged cortical seizures can result in distal injury in those regions (42).

In the present study in fetal sheep, the effective dose was some orders of magnitude lower than that reported in the adult rat (29), particularly if the relative difference in brain weight between the adult rat ( $\sim 1$ gram) and the fetal sheep ( $\sim 45$ grams) is considered. Moreover, the dose-response curve was bell-shaped, as $1 \mu \mathrm{g}$ rhIGF-1 was more effective than $0.1 \mu \mathrm{g}$, but $10 \mu \mathrm{g}$ was ineffective. The difference in dose between the adult rat and fetal sheep is not unexpected, and possibly relates to IGF-1 amino acid sequence differences between rat and sheep, rather than a developmental effect. Our fetal sheep were treated with recombinant human IGF-1, in which the sequence differs from that of ovine IGF-1 by only one amino acid (43). In contrast, there are greater differences in structure between rat and human IGF-1 (43). Consequently, the dose of rhIGF-1 required to produce metabolic or somatotrophic effects in the rat (44-46) is much higher than the dose of rhIGF-1 required to produce comparable effects in either the sheep (47) or human (48). Thus, the differences we observed in therapeutic dose may be the result of a differing affinity of rhIGF-1 for either rat IGF-1 receptors or rat IGF binding proteins (IGFBPs).

Explanations for the bell-shaped dose response curve, whereby the neuronal rescue effect of rhIGF-1 was lost at higher doses, are less obvious. However, such dose response curves are common in growth factor biology and biphasic effects of IGF-1 have been noted in vitro (49). In vivo, the IGFBPs fulfill a crucial role in modulating the physiological actions of the IGFs, and the bell-shaped dose-response curve we observed may relate to altered IGFBP availability or function after ischemic brain injury. To date six IGFBPs have been identified which belong to a family of structurally related peptides that bind the IGFs with an affinity similar to that of the IGF receptors. Certain IGFBPs may either inhibit the actions of IGF-1 by binding free IGF-1 and maintaining it in an inactive state, or they may potentiate IGF-1's actions by associating with the cell membrane and facilitating the interaction between IGF-1 and its receptor. In infant rats there is a marked change in IGFBP expression after unilateral hypoxic-ischemic brain injury $(21,22,50)$ and IGFBP-2 is expressed together with IGF-1 during myelin regeneration after spinal cord injury (51). Recent studies suggest that the IGFBPs are important determinants of the neuronal rescue effects of IGF-1 (52). Moreover, in sheep choroid plexus cells IGFBP2 has been shown to enhance the biological actions of IGF-1 at low concentrations, but to inhibit the actions of IGF-1 at high concentrations (53).

The primary mechanism whereby rhIGF-1 acts to promote neuronal rescue after cerebral hypoxia-ischemia awaits resolution. In recent years it has become apparent that a major proportion of neuronal death which results from defined episodes of cerebral hypoxia-ischemia evolves over a period from 8 to $48 \mathrm{~h}$ after the initial injury, rather than occurring during the insult itself (54). The cascade of cytotoxic processes which ultimately results in delayed neuronal death has been well described $(5,54,55)$, and recent evidence suggests apoptosis as an additional mechanism of selective neuronal death after ischemic injury (6-9). Since in the present study, rhIGF-1 treatment was not started until $2 \mathrm{~h}$ after insult, it is reasonable to assume that IGF-1 acts to interrupt mechanisms associated with delayed cell death, an assumption reinforced by previous findings in adult rats where rhIGF-1 was not neuro-protective when given $1 \mathrm{~h}$ before insult (29). In vitro, neurotrophic actions of IGF-1 are well documented $(25,28)$, and it is an essential survival factor for certain cell types in culture $(26,27)$. Recent studies demonstrate an action of IGF-1 in inhibiting apoptotic (56-59), hypoglycemic (60), or cycloheximide-induced (61) cell death. We speculate, therefore that exogenous administration of rhIGF-1 may promote neuronal survival after hypoxic-ischemic injury by providing trophic support and inhibiting the apoptotic cascade.

Perinatal hypoxic-ischemic injury continues to be an important cause of persistent neurological handicap or mortality, and is estimated to affect up to $0.6 \%$ of term infants (62) and $5-25 \%$ of premature babies (63). While there has been controversy as to whether intrapartum events lead to neurological sequelae, recent studies using magnetic resonance spectroscopy show that birth asphyxia can lead to an evolving encephalopathy with a delayed phase of cerebral energy dysfunction comparable to that observed in our preparation (3). In our model of perinatal hypoxic-ischemic encephalopathy, we have dem- 
onstrated a significant improvement in outcome after central administration of a single dose of rhIGF-1 given $2 \mathrm{~h}$ after injury. Promotion of neuronal rescue was observed over a relatively broad dose range and was achieved without evidence of toxic systemic side-effects, such as hypotension, hypoglycemia, or deterioration in blood gases during the five day period after rhIGF-1 administration. Thus, the present study suggests the therapeutic potential of rhIGF-1 as a neuronal rescue agent after perinatal hypoxic-ischemic injury. Currently, therapeutic options are essentially limited to support measures, as most other recently developed neuroprotective agents such as calcium channel antagonists, gangliosides, NMDA receptor antagonists and free radical scavengers exhibit beneficial effects only when administered before the injury. Moreover, use of certain neuroprotective agents, including the calcium channel antagonists and the NMDA receptor blockers has been associated with toxic systemic side effects such as hypotension. While the necessity for rhIGF-1 to be administered directly into the brain will limit its therapeutic potential to particular situations, the asphyxiated neonate is one instance where IGF-1 therapy may be practical because of access via the fontanelle. In addition, we have preliminary experimental evidence in the rat that ${ }^{3} \mathrm{H}-\mathrm{IGF}-1$ administered by spinal injection reaches the injured cerebral hemispheres (E. Sirimanne and P. D. Gluckman, unpublished observations). Further experimental studies are needed to determine long term outcome, and to be clinically practical a longer period between the insult and treatment would be desirable. In the adult rat, there was no evidence of adverse effects when IGF-1 was administered prior to hypoxic ischemic injury (29) which suggests that even if there is diagnostic uncertainty IGF-1 treatment may be useful. However, more extensive toxicological studies are indicated. Such studies may allow IGF-1 to be considered in situations such as perinatal encephalopathy where recent advances in the use of electroencephalographic techniques (64), cortical impedance monitoring (65), and near infrared spectroscopy (66) are enhancing clinicians' ability to identify asphyxiated infants before the onset of the secondary phase of brain injury.

\section{Acknowledgments}

We thank Linley Nisbet for her great skill and expertise in performing the fetal surgeries, and Tony Mekkleholt for surgical assistance.

This research was supported by grants from the Health Research Council of New Zealand. Supplies of rhIGF-1 were generously donated by Kabi Pharmacia, Stockholm, Sweden.

\section{References}

1. Williams, C. E., A. J. Gunn, P. D. Gluckman, and B. Synek. 1990. Delayed seizures occurring with hypoxic-ischemic encephalopathy in the fetal sheep. Pediatr. Res. 27:561-565.

2. Williams, C. E., A. J. Gunn, and P. D. Gluckman. 1991. The time course of intracellular edema and epileptiform activity following prenatal cerebral ischemia in sheep. Stroke. 22:516-521.

3. Wyatt, J. S., A. D. Edwards, D. Azzopardi, and E. O. Reynolds. 1989. Magnetic resonance and near infrared spectroscopy for investigation of perinatal hypoxic-ischaemic brain injury. Arch. Dis. Child. 64:953-963.

4. Azzopardi, D., J. S. Wyatt, E. B. Cady, D. T. Delpy, J. Baudin, A. L. Stewart, P. L. Hope, P. A. Hamilton, and E. O. Reynolds. 1989. Prognosis of newborn infants with hypoxic-ischemic brain injury assessed by phosphorus magnetic resonance spectroscopy. Pediatr Res. 25:445-451.

5. Vannucci, R. C. 1993. Mechanisms of perinatal hypoxic-ischemic brain damage. Semin. Perinatol. 17:330-337.

6. Macmanus, J. P., A. M. Buchan, I. E. Hill, I. Rasquinha, and E. Preston.
1993. Global ischemia can cause DNA fragmentation indicative of apoptosis in rat brain. Neurosci. Lett. 164:89-92.

7. Sei, Y., D. K. J. E. Vonlubitz, A. S. Basile, M. M. Borner, R. C. S. Lin, P. Skolnick, and L. H. Fossom. 1994. Internucleosomal DNA Fragmentation in Gerbil Hippocampus Following Forebrain Ischemia. Neurosci. Lett. 171:179182.

8. Mehmet, H., X. Yue, M. V. Squier, A. Lorek, E. Cady, J. Penrice, C. Sarraf, M. Wylezinska, V. Kirkbride, C. Cooper, G. C. Brown, J. S. Wyatt, E. O. R. Reynolds, and A. D. Edwards. 1994. Increased apoptosis in the cingulate sulcus of newborn piglets following transient hypoxia-ischaemia is related to the degree of high energy phosphate depletion during the insult. Neurosci. Lett. 181: 121-125.

9. Beilharz, E. J., C. E. Williams, M. Dragunow, E. Sirimanne, and P. D. Gluckman. 1995. Mechanisms of delayed cell death following hypoxic-ischemic injury in the immature rat: evidence for apoptosis during selective neuronal loss. Mol. Brain Res. 29:1-14.

10. Nieto-Sampedro, M., E. R. Lewis, C. W. Cotman, M. Manthorpe, S. D. Skaper, G. Barbin, F. M. Longo, and S. Varon. 1982. Brain injury causes a timedependent increase in neurotrophic activity at the lesion site. Science (Wash. DC). 217:860-861

11. Sara, V. R., K. Uvnas-Moberg, B. Uvnas, K. Hall, L. Wetterberg, B. Posloncec, and M. Goiny. 1982. The distribution of somatomedins in the nervous system of the cat and their release following neural stimulation. Acta Physiol. Scand. 115:467-470.

12. Rotwein, P., S. K. Burgess, J. D. Milbrandt, and J. E. Krause. 1988. Differential expression of insulin-like growth factor genes in rat central nervous system. Proc. Natl. Acad. Sci. USA. 85:265-269.

13. Baskin, D. G., B. J. Wilcox, D. P. Figlewicz, and D. M. Dorsa. 1988. Insulin and insulin-like growth factors in the CNS. TINS. 11:107-111.

14. Sara, V., K. Hall, H. von Holtz, R. Humbel, B. Sjorgen, and L. Wetterberg. 1982. Evidence for the presence of receptors for insulin-like growth factors 1 (IGF-1) and 2 (IGF-2) and insulin throughout the adult human brain. Neurosci. Lett. 34:39-44.

15. Gammeltoft, S., G. K. Haselbacher, R. E. Humbel, M. Fehlmann, and E. Van Obberghen. 1985. Two types of receptor for insulin-like growth factors in mammalian brain. EMBO (Eur. Mol. Biol. Organ.) J. 4:3407-3412.

16. Bohannon, N. J., E. S. Corp, B. J. Wilcox, D. P. Figlewicz, D. M. Dorsa, and D. G. Baskin. 1988. Localization of binding sites for insulin-like growth factor-1 (IGF-1) in the rat brain by quantitative autoradiography. Brain Res. 444: 205-213.

17. Bach, M. A., Z. Shen Orr, W. L. J. Lowe, C. T. J. Roberts, and D. LeRoith. 1991. Insulin-like growth factor I mRNA levels are developmentally regulated in specific regions of the rat brain. Mol. Brain Res. 10:43-48.

18. Werner, H., M. Woloschak, M. Adamo, Z. Shen-Orr, C. T. Roberts, Jr. and D. LeRoith. 1989. Developmental regulation of the rat insulin-like growth factor I receptor gene. Proc. Natl. Acad. Sci. USA. 86:7451-7455.

19. Garcia-Segura, L. M., J. Perez, S. Pons, M. T. Rejas, and I. Torres-Aleman. 1991. Localization of insulin-like growth factor1(IGF-1)-like immunoreactivity in the developing and adult rat brain. Brain Res. 560:167-174.

20. Mueller, R. V., T. K. Hunt, A. Tokunaga, and E. M. Spencer. 1994. The effect of insulinlike growth factor I on wound healing variables and macrophages in rats. Arch. Surg. 129:262-265.

21. Gluckman, P. D., N. D. Klempt, J. Guan, E. C. Mallard, E. Sirimanne, M. Dragunow, M. Klempt, K. Singh, C. E. Williams, and K. Nikolics. 1992. A role for IGF-1 in the rescue of CNS neurons following hypoxic-ischemic injury. Biochem. Biophys. Res. Commun. 182:593-599.

22. Beilharz, E. J., N. D. Klempt, M. Klempt, E. Sirimanne, M. Dragunow, and P. D. Gluckman. 1993. Differential expression of insulin-like growth factor binding proteins (IGFBP) 4 and 5 mRNA in the rat brain after transient hypoxic-ischemic injury. Mol. Brain Res. 18:209-215.

23. Lee, W. H., J. A. Clemens, and C. A. Bondy. 1992. Insulin-like growth factors in the response to cerebral ischemia. Mol. Cell. Neurosci. 3:36-43.

24. Yamaguchi, F., T. Itano, O. Miyamoto, N. A. Janjua, T. Ohmoto, K. Hosokawa, and O. Hatase. 1991. Increase of extracellular insulin-like growth factor 1(IGF-1) concentration following electrolytical lesion in rat hippocampus. Neurosci. Lett. 128:273-276.

25. Knusel, B., P. P. Michel, J. S. Schwaber, and F. Hefti. 1990. Selective and nonselective stimulation of central cholinergic and dopaminergic development in vitro by nerve growth factor, basic fibroblast growth factor, epidermal growth factor, insulin and the insulin-like growth factors 1 and 2. J. Neurosci. 10(2):558-570.

26. Svrzic, D., and D. Schubert. 1990. Insulin-like growth factor 1 supports embryonic nerve cell survival. Biochem. Biophys. Res. Commun. 172(1):54-60.

27. Barres, B. A., I. K. Hart, H. S. R. Coles, J. F. Burne, J. T. Voyvodic, W. D. Richardson, and M. C. Raff. 1992. Cell Death in the Oligodendrocyte Lineage. J. Neurobiol. 23:1221-1230.

28. Kanje, M., A. Skottner, J. Sjoberg, and G. Lundborg. 1989. Insulin-like growth factor 1 (IGF-1) stimulates regeneration of the rat sciatic nerve. Brain Res. 486:396-398.

29. Guan, J., C. E. Williams, M. Gunning, E. C. Mallard, and P. D. Gluckman. 1993. The effects of IGF-1 treatment after hypoxic-ischemic brain injury in adult rats. J. Cereb. Blood Flow Metab. 13:609-616. 
30. Bennet, L., P. D. Gluckman, B. M. Johnston, and W. W. Vale. 1990. The effects of corticotrophin releasing factor and two antagonists on breathing movements in fetal sheep. J. Physiol. 421:1-12.

31. Schlaefke, M. E., W. E. See, and H. Loeschcke. 1970. Ventilatory response to alterations of $\mathrm{H}+$ ion concentrations in small areas of the ventral medullary surface. Resp. Physiol. 10:198-212.

32. Williams, C. E., and P. D. Gluckman. 1990. Real-time spectral intensity analysis of the EEG on a microcomputer. J. Neurosci. Methods. 32:9-13.

33. Williams, C. E., A. J. Gunn, E. C. Mallard, and P. D. Gluckman. 1992. Outcome after ischemia in the developing sheep brain: An electroencephalographic and histological study. Ann. Neurol. 31:14-21.

34. Smith, M. L., R. N. Auer, and B. K. Siesjö. 1984. The density and distribution of ischemic brain injury in the rat following 2-10 min of forebrain ischemia. Acta Neuropathol. Berl. 64:319-332.

35. Yager, J., J. Towfighi, and R. C. Vannucci. 1993. Influence of mild hypothermia on hypoxic-ischemic brain damage in the immature rat. Pediatr. Res. 34:525-529.

36. Sirimanne, E. S., R. M. Blumberg, D. Bossano, M. I. Gunning, A. D. Edwards, P. D. Gluckman, and C. E. Williams. 1996. The effect of prolonged modification of cerebral temperature on outcome following hypoxic ischemic injury in the infant rat. Pediatr. Res. In press.

37. Groenendaal, F., R. H. Veenhoven, J. van der Grond, G. H. Jansen, T. D. Witkamp, and L. S. De Vries. 1994. Cerebral lactate and N-acetyl-aspartate/choline ratios in asphyxiated full-term neonates demonstrated in vivo using proton magnetic resonance spectroscopy. Pediatr. Res. 35:148-151.

38. Klein, H. C., W. Krop Van Gastel, K. G. Go, and J. Korf. 1993. Prediction of specific damage or infarction from the measurement of tissue impedance following repetitive brain ischaemia in the rat. Neuropathol. Appl. Neurobiol. 19:57-65.

39. Ocrant, I., K. L. Valentino, L. F. Eng, R. L. Hintz, D. M. Wilson, and R. G. Rosenfeld. 1988. Structural and immunohistochemical characterization of insulin-like growth factor I and II receptors in the murine central nervous system. Endocrinology. 123:1023-1034.

40. Bondy, C., H. Werner, C. T. Roberts, Jr., and D. LeRoith. 1992. Cellular pattern of type-I insulin-like growth factor receptor gene expression during maturation of the rat brain: comparison with insulin-like growth factors I and II. Neurosci. 46:909-923.

41. Mallard, E. C., C. E. Williams, B. M. Johnston, M. I. Gunning, S. L. Davis, and P. D. Gluckman. 1995. Repeated episodes of umbilical cord occlusion in fetal sheep lead to preferential damage to the striatum and sensitise the heart to further insults. Pediatr. Res. 37:707-713.

42. Tan, W. K. M., C. E. Williams, A. J. Gunn, C. E. Mallard, and P. D. Gluckman. 1992. Suppression of postischemic epileptiform activity with MK801 improves neural outcome in fetal sheep. Ann. Neurol. 32:677-682.

43. Wong, E. A., S. M. Ohlsen, J. A. Godfredson, D. M. Dean, and J. E. Wheaton. 1989. Cloning of Ovine insulin-like growth factor-1 cDNAs: Heterogeneity in the mRNA population. DNA. 8(9):649-657.

44. Guler, H. P., J. Zapf, and E. R. Froesch. 1987. Short term metabolic effects of recombinant human IGF in healthy adults. N. Engl. J. Med. 317:137140.

45. Guler, H.-P., J. Zapf, E. Scheiwiller, and E. R. Froesch. 1988. Recombinant human insulin-like growth factor I stimulates growth and has distinct effects on organ size in hypophysectomised rats. Proc. Natl. Acad. Sci. USA. 85: 4889-4893.

46. Skottner, A., R. G. Clark, L. Fryklund, and I. C. A. F. Robinson. 1989. Growth responses in a mutant dwarf rat to human growth hormone and recombinant human insulin-like growth factor I. Endocrinology. 124:2519-2526.

47. Douglas, R. G., P. D. Gluckman, K. Ball, B. H. Breier, and J. H. Shaw. 1991. The effects of infusion of insulinlike growth factor (IGF) I, IGF-II, and insulin on glucose and protein metabolism in fasted lambs. J. Clin. Invest. 88: 614-622.

48. Laron, Z., S. Anin, Y. Klipper-Aurbach, and B. Klinger. 1992. Effects of insulin-like growth factor on linear growth, head circumference, and body fat in patients with Laron-type dwarfism. Lancet. 339:1258-1261.

49. Florini, J. R., D. Z. Ewton, S. L. Falen, and J. J. Van Wyk. 1986. Biphasic concentration dependency of stimulation of myoblast differentiation by somatomedins. Am. J. Physiol. 250:C771-C778.

50. Klempt, N. D., M. Klempt, A. J. Gunn, K. Singh, and P. D. Gluckman 1992. Expression of insulin-like growth factor binding protein-2(IGF-BP-2) following transient hypoxia-ischemia in the infant rat brain. Mol. Brain. Res. 15: 55-61.

51. Yao, D. L., N. R. West, C. A. Bondy, M. Brenner, L. D. Hudson, J. Zhou, G. H. Collins, and H. D. Webster. 1995. Cryogenic spinal cord injury induces astrocytic gene expression of insulin-like growth factor I and insulin-like growth factor binding protein 2 during myelin regeneration. J. Neurosci. Res. 40:647-659.

52. Guan, J., C. E. Williams, E. C. Mallard, E. Sirimanne, and P. D. Gluckman. 1996. The effects of IGF-1, IGF-2 and des IGF-1 on neuronal loss after hypoxic ischemic brain injury in adult rats: Evidence for a role for IGF binding proteins. Endocrinology. In press.

53. Delhanty, P. J. D., and V. K. M. Han 1993. An RGD to RGD mutation in the putative membrane binding domain of IGFBP-2 inhibits its potentiation of IGF-2 induced thymidine uptake by SCP cells. 75th Annual Meeting Endocrine Soci. p. 56 Abstract 22.

54. Gluckman, P. D., and C. E. Williams. 1992. When and why do brain cells die? Dev. Med. Child Neurol. 34:1010-1014.

55. Fawthrop, D. J., A. R. Boobis, and D. S. Davise. 1991. Mechanisms of cell death. Arch. Toxicol. 65:437-444.

56. Rodriguez-Tarduchy, G., M. K. L. Collins, I. Garcia, and A. LopezRivas. 1992. Insulin like-growth factor-1 inhibits apoptosis in IL-3-dependent hemopoietic cells. J. Immunol. 149:535-540.

57. Neff, N. T., D. Prevette, L. J. Houenou, M. E. Lewis, M. A. Glicksman, Q-W. Yin, and R. W. Oppenheim. 1993. Insulin-like growth factors: Putative muscle-derived trophic agents that promote motoneuron survival. J. Neurobiol. 24:1578-1588

58. D'Mello, S. R., C. Galli, T. Ciotti, and P. Calissano. 1993. Induction of apoptosis in cerebellar granule neurons by low potassium: inhibition of death by insulin-like growth factor I and cAMP. Proc. Natl. Acad. Sci. USA. 90: 10989-10993.

59. Galli, C., O. Meucci, A. Scorziello, T. M. Werge, P. Calissano, and G. Schettini. 1995. Apoptosis in cerebellar granule cells is blocked by high $\mathrm{KCl}$, forskolin, and IGF-1 through distinct mechanisms of action: The involvement of intracellular calcium and RNA synthesis. J. Neurosci. 15:1172-1179.

60. Cheng, B., and M. P. Mattson. 1992. IGF-I and IGF-II protect cultured hippocampal and septal neurons against calcium-mediated hypoglycemic damage. J. Neurosci. 12:1558-1566.

61. Geier, A., M. Haimshon, R. Beery, R. Hemi, and B. Lunenfeld. 1992. Insulinlike growth factor-1 inhibits cell death induced by cycloheximide in MCF-7 cells-a model system for analyzing control of cell death. In Vitro Cell Dev. Biol-Animal. 28A:725-729.

62. Levene, M. I., J. Kornberg, and T. H. C. Williams. 1985. The incidence and severity of post asphyxial encephalopathy in fullterm infants. Early Hum. Dev. 11:21-28.

63. Volpe, J. J. 1992. Brain injury in the premature infant-Current concepts of pathogenesis and prevention. Biol. Neonate. 62:231-242.

64. Hellstrom Westas, L., I. Rosen, and N. W. Svenningsen. 1995. Predictive value of early continuous amplitude integrated EEG recordings on outcome after severe birth asphyxia in full term infants. Arch. Dis. Child. 72:F34$\mathrm{F} 38$.

65. Gunn, A. J., T. R. Gunn, C. E. Williams, and S. L. Davis. 1995. Changes in cortical impedance during perinatal hypoxic-ischemic encephalopathy (HIE). Pediatr. Res. 37:208a (Abstr.).

66. Marks, K., E. C. Mallard, I. Roberts, C. E. Williams, E. S. Sirimanne, B. M. Johnston, P. D. Gluckman, and A. D. Edwards. 1996. Delayed vasodilation and altered oxygenation following cerebral ischemia in fetal sheep. Pediatr. Res. In press. 